\title{
The dangers of lithotomy positioning in the operating room: case report of bilateral lower extremity compartment syndrome after a 90-minutes surgical procedure
}

\author{
Nicole Stornelli ${ }^{1}$, Frank B. Wydra ${ }^{2}$, Justin J. Mitchell ${ }^{2}$, Philip F. Stahel ${ }^{2}$ and Stefka Fabbri ${ }^{* *}$
}

\begin{abstract}
Background: Lower extremity acute compartment syndrome after gynecologic surgery in the lithotomy position is a rare, yet potentially devastating complication. A high level of suspicion is paramount for early recognition and mitigation of acute compartment syndrome originating from prolonged surgery in lithotomy position.

Case presentation: A 23-year-old female, gravida 1, para 0, underwent a laparoscopic salpingectomy for a ruptured ectopic pregnancy. Surgical time was $90 \mathrm{~min}$. Postoperatively, the patient developed acute compartment syndrome of both legs necessitating emergent bilateral four-compartment fasciotomies, with repeated returns to the operating room for 2 nd look procedures and delayed wound closures. The patient regained full function within 3 months and returned to an unrestricted baseline activity level.

Conclusion: Technical diligence in applying a lithotomy position is paramount for preventing postoperative lower extremity compartment syndrome. A high level of suspicion for this severe complication in conjunction with early recognition and immediate surgical management can mitigate long-term adverse sequelae and improve postoperative outcomes.
\end{abstract}

Keywords: Compartment syndrome, Fasciotomy, Lithotomy position, Surgical complication, Adverse event, Patient safety

\section{Background}

Acute compartment syndrome (ACS) of the lower extremities is a known complication after surgical positioning in lithotomy or hemilithotomy position [1-3]. As most gynecological procedures require a lithotomy position by default, these patients are at particular risk for developing postoperative compartment syndrome, particularly after prolonged surgical procedures lasting beyond $2-4 \mathrm{~h}[4,5]$. Although a rare complication, delayed diagnosis of ACS can lead to irreversible muscle necrosis with the potential for debilitating lower extremity dysfunction and a high risk for requiring delayed lower limb amputations [6, 7]. Thus, prompt recognition and surgical intervention are

\footnotetext{
* Correspondence: stefka.taskaeva@dhha.org

'Department of Obstetrics and Gynecology, Denver Health Medical Center and University of Colorado School of Medicine, Denver, CO 80204, USA Full list of author information is available at the end of the article

paramount for mitigating this severe postoperative complication [8-10]. The large bulk of the existing literature on ACS secondary to lithotomy positioning are case reports either of prolonged surgical procedures beyond $4 \mathrm{~h}$, or restricted to unilateral well-leg compartment syndrome $[11,12]$. In this report, we describe the rare case of a young 23-year old patient who developed bilateral lower extremity ACS following a routine 90-min laparoscopic salpingectomy in lithotomy position for an ectopic pregnancy. Tips and tricks on how to prevent and mitigate this severe intraoperative complication are discussed.

\section{Case presentation}

A 23-year-old woman, gravida 1, para 0 , at unknown gestational age presented to our emergency department with lower abdominal pain, vaginal spotting, and lightheadedness for 2 days. The patient's medical history was 
significant for morbid obesity with body mass index, history of Chlamydia infection and pelvic inflammatory disease at age 15, and laparoscopic cholecystectomy at age 19. Physical examination including a transvaginal ultrasonographic evaluation revealed a ruptured ectopic pregnancy. The patient was hemodynamically stable and underwent a laparoscopic right salpingectomy. The procedure was performed in a standard "low" lithotomy position (using Allen ${ }^{\circ}$ stirrups). Care was taken not to flex hips or knees beyond $90^{\circ}$, with hip abduction less than $45^{\circ}$ and neutral hip rotation (Fig. 1). The patient was in Trendelenburg position to allow for adequate visualization of the pelvis. Pneumatic compression devices on both calves were in place throughout the procedure. Skin-toskin surgical time was $90 \mathrm{~min}$ due to the need for lysis of omental adhesion and the presence of pelvic adhesive disease consistent with the patient's prior surgical and gynecologic history. Intraoperative findings and pathologic evaluation confirmed the diagnosis of a ruptured ectopic pregnancy. Immediately upon awakening from general anesthesia, the patient complained of severe bilateral calf pain. Initial evaluation of the lower extremities revealed no compression marks, ecchymoses, erythema or edema, and the peripheral neurovascular exam was unremarkable. Serum electrolytes were within normal limits. Serum creatine kinase (CK) was elevated at 22,760 units/L (Norm: 38-176 units/L), consistent with rhabdomyolysis. An urgent bilateral lower extremity Doppler ultrasound was obtained which ruled out a deep venous thrombosis. The patient was treated symptomatically with analgesics and muscle relaxants. As her pain continued to escalate, a concern for acute compartment syndrome (ACS) was raised and the orthopedic surgery service was consulted. Based on the high level of suspicion for ACS in light of the clinical exam and exacerbating pain out of proportion, the patient was taken back emergently to the operating room by the orthopedic surgery team for bilateral lower extremity four-compartment fasciotomies. Surgery was accomplished approximately $8 \mathrm{~h}$ after her initial laparoscopic surgery. Intraoperatively, the diagnosis of ACS was confirmed. All muscles in the four compartments in bilateral legs were viable on clinical exam and bovie stimulation testing, without any signs of muscle necrosis. The patient required two additional staged surgical procedures for scheduled 2nd looks, soft tissue debridement and delayed primary wound closures. Her serum CK decreased to 1278 units/L prior to discharge and she did not sustain any renal failure or crush syndrome throughout the hospitalisation. The patient's serum creatinine remained in a normal range of $0.6-0.8 \mathrm{mg} / \mathrm{dL}$ (Norm: $0.5-1.0 \mathrm{mg} / \mathrm{dL}$ ). She was discharged home on postoperative day four after definitive wound closure, with home physical therapy arranged. She had an uneventful further recovery, with pristine wound healing, no infection and a normal neurovascular status on bilateral lower extremities on follow-up exam. By 3 months after discharge from the hospital, she had regained full unrestricted function and a normal quality of life.

\section{Discussion}

We present a rare case of bilateral lower extremity acute compartment syndrome that developed in a healthy 23-year-old female after undergoing a laparoscopic salpingectomy for ruptured ectopic pregnancy in the usual lithotomy position. This case highlights a rare complication that has been previously associated with lithotomy or hemilithotomy positioning $[2,5,12,13]$. Lower extremity ACS is a pathologic condition in which increased tissue pressure within a closed osseofascial space compromises blood circulation and normal function of tissues within the compartment leading to tissue hypoxia and necrosis $[8,14]$. If left untreated, patients with ACS can develop muscle contracture, sensory deficits, paralysis, possible need for limb amputation, and potentially multi-system

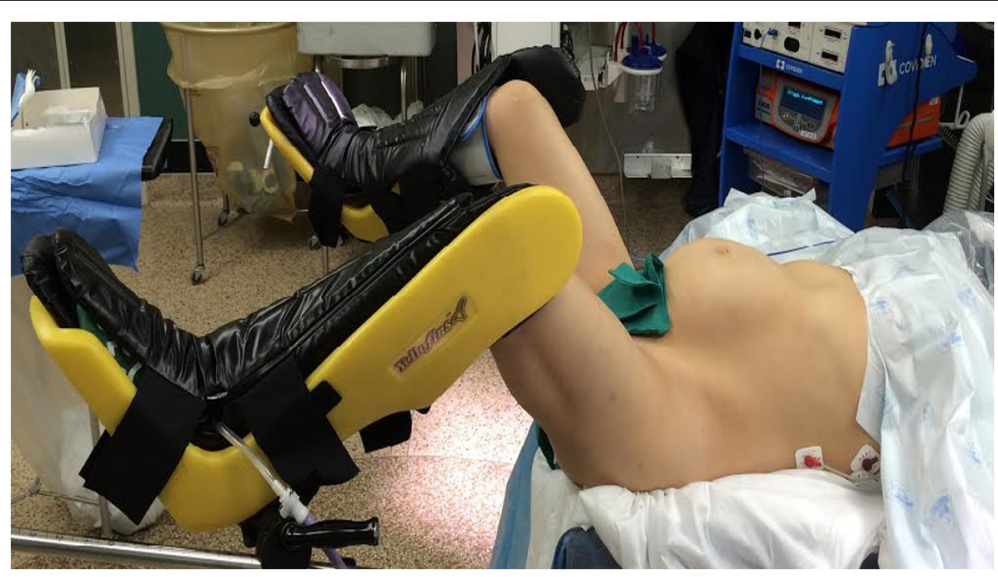

Fig. 1 Demonstration of lithotomy position technique applied at the authors' institution 
organ failure secondary to crush syndrome $[15,16]$. The osseofascial lining of the four lower extremity compartments (anterior, lateral, superficial and deep posterior) form an enclosed environment of muscle, blood vessels and nerves with limited ability to expand or accommodate increased volume or pressure $[8,17]$. ACS in the postoperative state occurs as a result of intraoperative compression with a prolonged decrease in arterial pressure and/or increase in venous pressure, followed by reperfusion [18]. Local ischemia can subsequently damage endothelial cells resulting in leakage of proteins and fluid into the interstitial space. The subsequent increase in interstitial pressure elevates compartmental pressures, thus perpetuating the cycle of hypoperfusion and tissue ischemia [19]. Specifically, in the lithotomy position, ischemia occurs from compressive forces of the external leg holsters and diminished blood flow from leg elevation and kinking of the popliteal artery, leading to ischemia/reperfusion injury with subsequent compartment syndrome [1]. When the lower extremities are taken out of lithotomy position and elevation, limb reperfusion occurs and can lead to injury with the formation of oxygen free radicals and cytokines that perpetuate endothelial damage and interstitial edema [20]. In addition to lithotomy position, other risk factors associated with ACS after surgery include: ankle dorsiflexion, Trendelenburg position, leg holders, length of surgery greater than $2 \mathrm{~h}$, intraoperative hypotension or hypovolemia, and epidural analgesia [1]. Bauer and colleagues recently published two articles documenting cases of lower extremity ACS following gynecologic surgery in the lithotomy position and found that the vast majority of ACS cases occurred following procedures lasting longer than $4 \mathrm{~h}[4,12]$. Other studies have demonstrated that calf compartment pressure increases at a rate of $1.1 \mathrm{mmHg}$ per hour in the lithotomy position [1]. In addition, elevation of the leg above heart level ("high" lithotomy positon) has been associated with increased risk of compartment syndrome [21]. Intermittent pneumatic compressive devices used for the prevention of deep venous thrombosis intraoperatively, as applied in the patient presented in this case report, have also been identified as causative factors for ACS [22]. We postulate that lithotomy with adjunctive Trendelenburg position was likely the contributory root cause of bilateral lower extremity ACS in the young 23-old patient described in this case report. Multiple technical tricks have been described to prevent ACS in lithotomy position, including intraoperative repositioning of the legs, avoiding pressure in the popliteal fossa and kinking of the popliteal artery by avoiding knee flexion beyond $90^{\circ}[1,23]$. Lower extremity ACS remains a clinical diagnosis, and immediate recognition and surgical management are paramount in avoiding long-term impairment and poor outcomes [14]. The most common clinical symptom is represented by uncontrolled pain out of proportion and exacerbated pain by passive stretch of the toes and ankle joint [14]. Measurement of the compartment pressure can aid in the diagnosis, albeit there is dispute among orthopedic surgeons regarding the pressure threshold for the diagnosis of ACS and subsequent need for fasciotomy. The most effective method of diagnosis of ACS remains a clinical diagnosis requiring a high level of suspicion by the treating physician. Given the short duration of our patient's procedure and lack of risk factors with the exception of lithotomy position and her full recovery after immediate recognition and surgical management, our case highlights the imperative of understanding the pathophysiology of ACS in lithotomy position and raising a high level of suspicion in a patient with postoperative calf pain after gynecological procedures.

\section{Conclusion}

ACS is a rare but serious complication from surgical procedures performed in the lithotomy or hemilithotomy position. The greatest risk factor for major sequelae from ACS is failure to recognize and manage this condition in a timely fashion when a postoperative patient presents with increasing leg pain after surgery. Recommendations to prevent intraoperative development of a compartment syndrome include correct patient positioning [1, 23], utilizing well-padded stirrups for the lower extremity, to limit the duration in lithotomy position whenever possible, and to reposition and mobilize the knees and legs if procedures extend beyond $2 \mathrm{~h}$ of surgical time.

\section{Abbreviations \\ ACS, acute compartment syndrome; CK, creatinine kinase}

\section{Acknowledgments}

N/A.

\section{Funding}

The publication costs for this article were covered in full by a grant from the Colorado Physician Insurance Company (COPIC) to Philip F. Stahel, MD.

COPIC had no influence on authorship or scientific content of this article.

\section{Availability of data and materials}

N/A.

\section{Authors' contributions}

NS carried out the literature review and drafting of the first version of the initial manuscript. FBW, JJM, and PSF provided critical revisions and drafting of the final version of the manuscript. SF and PFS were responsible for the surgical management of the patient described in this report. All authors read and approved the final version of this manuscript prior to submission.

\section{Competing interests}

The authors declare that they have no competing interests.

Consent for publication

Written informed consent was obtained from the patient for publication of this case report. 


\section{Ethics approval and consent to participate}

$\mathrm{N} / \mathrm{A}$.

\section{Author details}

'Department of Obstetrics and Gynecology, Denver Health Medical Center and University of Colorado School of Medicine, Denver, CO 80204, USA. ${ }^{2}$ Department of Orthopaedic Surgery, Denver Health Medical Center and University of Colorado School of Medicine, Denver, CO 80204, USA.

Received: 17 May 2016 Accepted: 12 July 2016

Published online: 26 July 2016

\section{References}

1. Flierl MA, Stahel PF, Hak DJ, Morgan SJ, Smith WR. Traction table-related complications in orthopaedic surgery. J Am Acad Orthop Surg. 2010;18(11): 668-75.

2. Enomoto T, Ohara Y, Yamamoto M, Oda T, Ohkohchi N. Well leg compartment syndrome after surgery for ulcerative colitis in the lithotomy position: a case report. Int J Surg Case Rep. 2016;23:25-8.

3. Hsu KL, Chang CW, Lin CJ, Chang CH, Su WR, Chen SM. The dangers of hemilithotomy positioning on traction tables: case report of a well-leg drop foot after contralateral femoral nailing. Patient Saf Surg. 2015;9:18.

4. Bauer EC, Koch N, Erichsen CJ, Juettner T, Rein D, Janni W, Bender HG, Fleisch MC. Survey of compartment syndrome of the lower extremity after gynecological operations. Langenbecks Arch Surg. 2014;399(3):343-8.

5. Kikuchi T, Maeda H. Two cases of compartment syndrome of the lower extremities during surgery for gynecological malignancies. J Anesth. 2016:30:481-5.

6. Kent T, Yi C, Livermore M, Stahel PF. Skin grafts provide durable end-bearing coverage for lower-extremity amputations with critical soft tissue loss. Orthopedics. 2013;36(2):132-5.

7. Abdul W, Hickey B, Wilson C. Lower extremity compartment syndrome in the setting of iliofemoral deep vein thrombosis, phlegmasia cerulea dolens and factor VII deficiency. BMJ Case Rep 2016, 2016

8. von Keudell AG, Weaver MJ, Appleton PT, Bae DS, Dyer GS, Heng M, Jupiter JB, Vrahas MS. Diagnosis and treatment of acute extremity compartment syndrome. Lancet. 2015;386(10000):1299-310.

9. Sellei RM, Hingmann SJ, Kobbe P, Weber C, Grice JE, Zimmerman F, Jeromin S, Hildebrand F, Pape HC. Compartment elasticity measured by pressure-related ultrasound to determine patients "at risk" for compartment syndrome: an experimental in vitro study. Patient Saf Surg. 2015;9(1):4.

10. Kashuk JL, Moore EE, Pinski S, Johnson JL, Moore JB, Morgan S, Cothren CC, Smith W. Lower extremity compartment syndrome in the acute care surgery paradigm: safety lessons learned. Patient Saf Surg. 2009;3(1):11.

11. Boesgaard-Kjer DH, Boesgaard-Kjer D, Kjer JJ. Well-leg compartment syndrome after gynecological laparoscopic surgery. Acta Obstet Gynecol Scand. 2013;92(5):598-600

12. Bauer EC, Koch N, Janni W, Bender HG, Fleisch MC. Compartment syndrome after gynecologic operations: evidence from case reports and reviews. Eur J Obstet Gynecol Reprod Biol. 2014;173:7-12.

13. Beerle BJ, Rose RJ. Lower extremity compartment syndrome from prolonged lithotomy position not masked by epidural bupivacaine and fentanyl. Reg Anesth. 1993;18(3):189-90.

14. Harvey EJ, Sanders DW, Shuler MS, Lawendy AR, Cole AL, Alqahtani SM, Schmidt AH. What's new in acute compartment syndrome? J Orthop Trauma. 2012;26(12):699-702.

15. Genthon A, Wilcox SR. Crush syndrome: a case report and review of the literature. J Emerg Med. 2014;46(2):313-9.

16. Zutt R, van der Kooi AJ, Linthorst GE, Wanders RJ, de Visser M. Rhabdomyolysis: review of the literature. Neuromuscul Disord. 2014;24(8):651-9.

17. Raza H, Mahapatra A. Acute compartment syndrome in orthopedics: causes, diagnosis, and management. Adv Orthop. 2015;2015:543412.

18. Winston BA, VanSickle D, Winston KR. Resistance to venous flow: a mathematical description and implications for compartment syndromes. J Trauma Acute Care Surg 2016 (in press)

19. Hakaim AG, Cunningham L, White JL, Hoover K. Selective type III phosphodiesterase inhibition prevents elevated compartment pressure after ischemia/reperfusion injury. J Trauma. 1999;46(5):869-72.

20. Blaisdell FW. The pathophysiology of skeletal muscle ischemia and the reperfusion syndrome: a review. Cardiovasc Surg. 2002;10(6):620-30.
21. Tiwari A, Myint F, Hamilton G. Compartment syndrome. Eur J Vasc Endovasc Surg. 2002;24(5):469.

22. Raza A, Byrne D, Townell N. Lower limb (well leg) compartment syndrome after urological pelvic surgery. J Urol. 2004;171(1):5-11.

23. Tomassetti C, Meuleman C, Vanacker B, D'Hooghe T. Lower limb compartment syndrome as a complication of laparoscopic laser surgery for severe endometriosis. Fertil Steril. 2009;92(6):2038. e2039-2012.

\section{Submit your next manuscript to BioMed Central and we will help you at every step:}

- We accept pre-submission inquiries

- Our selector tool helps you to find the most relevant journal

- We provide round the clock customer support

- Convenient online submission

- Thorough peer review

- Inclusion in PubMed and all major indexing services

- Maximum visibility for your research

Submit your manuscript at www.biomedcentral.com/submit
Biomed Central 